\title{
Determinan Intensi Whistleblowing Internal pada OPD Kabupaten Purbalingga
}

\author{
Ningrum Pramudiati ${ }^{\bowtie}$, Rizki Nur Aziz \\ Universitas PGRI Yogyakarta \\ e-mail: pramudiati.ningrum@upy.ac.id
}

\begin{abstract}
This research aims to examine the determinants of internal whistleblowing intention at OPD Purbalingga Regency. The determinants of internal whistleblowing intention need to be examined because Indonesia is one of the countries with a high level of fraud. This research used primary data in the form questionnaires with purposive sampling method. The sample used in this study were 27 Regional Apparatus Organizations (OPD) in Purbalingga Regency, Central Java Province. The variables examined in this study were professional commitment, ethical environment, moral intensity, and personal cost. This research used descriptive analysis and multiple linear regression analysis. The results of this study indicate that professional commitment, ethical environment, moral intensity, and personal cost have a positive and partial effect on the intention to conduct internal whistleblowing at the Regional Apparatus Organization (OPD) of Purbalingga Regency. A person with a high moral intensity tends to have a high intensity to whistleblowing. This means that morals are often an important limitation for a person to take action. A person with high moral boundaries will not like anything beyond the existing moral rules.
\end{abstract}

Keywords: professional commitment, ethical environment, moral intensity, personal cost, whistleblowing

\begin{abstract}
Abstrak
Penelitian ini menguji determinan intensi whistleblowing internal pada OPD Kabupaten Purbalingga. Determinan intensi whistleblowing internal perlu diteliti karena Indonesia merupakan salah negara dengan tingkat kecurangan tingggi. Penelitian ini menggunakan metode purposive sampling yang diambil dari data primer kuesioner. Sampel yang digunakan dalam penelitian ini adalah 27 Organisasi Perangkat Daerah (OPD) di Kabupaten Purbalingga, Provinsi Jawa Tengah. Variabel yang diteliti dalam penelitian ini adalah komitmen profesional, lingkungan etika, intensitas moral, dan personal cost. Penelitian ini menggunakan analisis deskriptif dan analisis regresi linier berganda. Hasil penelitian ini menunjukkan bahwa komitmen profesional, lingkungan etika, intensitas moral, dan personal cost berpengaruh positif terhadap intensi untuk melakukan whistleblowing internal pada Organisasi Perangkat Daerah (OPD) Kabupaten Purbalingga. Seseorang dengan intensitas moral yang tinggi cenderung memiliki intensitas yang tinggi pula untuk melakukan whistleblowing. Artinya bahwa moral seringkali menjadi batasan penting bagi seseorang dalam melakukan tindakan. Seseorang dengan batasan moral yang tinggi tidak akan menyukai hal di luar aturan moral yang ada.
\end{abstract}

Kata kunci: komitmen profesional, lingkungan etika, intensitas moral, dan personal cost, whistleblowing internal 


\section{PENDAHULUAN}

Tindak kecurangan (fraud) di sektor swasta dan sektor publik masih memiliki persentase yang cukup tinggi. Informasi data yang dirilis oleh Transparency International, Corruption Perception Index (CPI) tahun 2019, Indonesia memperoleh score 40 dan berada dalam rank 85 dari total 180 negara yang disurvei. Hasil perolehan score tersebut menunjukkan persepsi korupsi di Indonesia naik 2 score dari tahun sebelumnya yaitu dengan perolehan score 38 (Corruption Perceptions Index, 2019). Kecurangan ini menjadi pusat perhatian serius dari masyarakat yang mengakibatkan menurunnya tingkat kepercayaan masyarakat terhadap aparatur pemerintah beserta instansinya yang melakukan tindakan kecurangan ini. Saat ini, hal ini masih sering menjadi berita hangat baik pro dan kontra di kalangan masyarakat (Putra \& Hariyani, 2018).

Salah satu jenis fraud yang sering terjadi serta menjadi perhatian khusus pada sektor publik Indonesia adalah korupsi. Korupsi merupakan tindakan melanggar hukum yang terjadi karena adanya penyalahgunaan wewenang dengan tujuan mendapat keuntungan bagi pribadi, orang lain maupun perusahaan yang dilakukan dengan berbagai cara yang tidak benar dan tidak sesuai dengan norma, etika, dan aturan yang berlaku (Auzan, 2018). Indonesia Corruption Watch (ICW) mengungkapkan bahwa Pemerintah Kabupaten merupakan lembaga yang mendominasi kasus korupsi di Indonesia tahun 2018. Kasus korupsi yang terjadi di pemerintah kabupaten merupakan kasus yang menduduki peringkat pertama berdasarkan pemetaan korupsi berdasarkan lembaga. Jumlah kasus korupsi yang terjadi sebanyak 170 kasus dengan nilai kerugian negara sebesar Rp.833 miliar. Jumlah pelaku yang ditetapkan sebagai tersangka dari tindak kecurangan korupsi di Pemerintah Kabupaten adalah sebanyak 390 orang. Salah satu bentuk kecurangan korupsi terjadi di daerah Kabupaten Purbalingga tahun 2018.
Komisi Pemberantasan Korupsi (KPK) menetapkan Bupati Purbalingga sebagai tersangka atas penerimaan suap atas fee pembangunan Purbalingga Islamic Center tahap kedua yaitu sebesar Rp 500 juta dari total anggaran pembangunan sebesar Rp 22 miliar (Risalah, 2018). Kasus kecurangan sering kali terungkap karena adanya pelapor yang melihat suatu indikasi masalah dan pelapor tersebut memiliki niat untuk mengungkapkannya ke publik (Sari \& Ariyanto, 2017). Upaya yang dilakukan untuk mengungkapkan kecurangan atau indikasi dari suatu masalah disebut dengan whistleblowing.

Whistleblowing merupakan salah satu cara yang efektif untuk efektif dan tepat untuk mencegah terjadinya suatu kecurangan ataupun pelanggaran yang mungkin akan terjadi (Janitra, 2017). Whistleblower (pelapor whistleblowing) akan melaporkan tindakan ilegal atau tindakan yang tidak sesuai dengan aturan dan kaidah moral yang berlaku kepada pihak internal maupun pihak eksternal organisasi (Zanaria, 2016).

Seseorang yang memiliki komitmen yang tinggi terhadap organisasi atau profesinya akan memiliki niat yang tinggi untuk memberikan yang terbaik terhadap organisasi atau profesi yang ditekuni. Whistleblowing adalah suatu tindakan melaporkan kecurangan yang terjadi akibat pelanggaran terhadap hukum, etika, dan moral oleh anggota organisasi. Tindakan kecurangan dan pelanggaran ini dapat menimbulkan kerugian terhadap organisasi, semua pemangku kepentingan yang terlibat (Komite Nasional Kebijakan Governance, 2008). Pelaporan atas tindakan pelanggaran dilakukan oleh seorang pelapor pelanggaran (whistleblower).

Komitmen profesional adalah keyakinan, penerimaan nilai-nilai dan tujuan organisasi atau profesi oleh anggota suatu organisasi dan adanya upaya untuk menjaga keanggotaan dalam organisasi atau profesi (Aranya dkk., 1981). Selain komitmen profesional, faktor lain yang mendorong intensi untuk melakukan 
whistleblowing yaitu lingkungan etika. Lingkungan etika adalah suatu keyakinan terhadap nilai-nilai moral organisasi atau profesi (Suzila, 2018). Faktor selanjutnya yang mendorong intensi untuk melakukan whistleblowing yaitu intensitas moral yang merupakan persepsi yang dimiliki seseorang untuk mengontrol dirinya sendiri (Kreshastuti \& Prastiwi, 2014). Personal cost juga menjadi salah satu pemicu pendorong intensi untuk melakukan whistleblowing. Personal cost merupakan keyakinan seseorang terhadap suatu sanksi atau hukuman jika seseorang berniat untuk melaporkan kecurangan dalam suatu organisasi atau profesi (Schultz dkk., 1993).

Terdapat hasil penelitian yang tidak konsisten dibeberapa penelitian terdahulu yang berkaitan dengan determinan intensi whistleblowing internal. Penelitian Janitra (2017), Putra \& Hariyani (2018), dan Amelia (2018) memberikan hasil, yaitu komitmen profesional berpengaruh terhadap intensi melakukan whistleblowing internal, sedangkan penelitian yang dilakukan Pangesti \& Rahayu (2017) komitmen profesional berpengaruh signifikan dan positif terhadap whistleblowing. Penelitian Hanif \& Odiatma (2017) memberikan hasil, yaitu lingkungan etika berpengaruh terhadap niat untuk melakukan whistleblowing, sedangkan penelitian Ahyaruddin \& Asnawi (2017) memberikan hasil, yaitu lingkungan etika tidak berpengaruh terhadap whistleblowing.

Penelitian Zanaria (2016), Husniati (2017), dan Putra \& Hariyani (2018) menunjukkan bahwa intensitas moral berpengaruh terhadap whistleblowing internal. Penelitian Kreshastuti \& Prastiwi (2014) menunjukkan bahwa intensitas moral berpengaruh positif signifikan terhadap intensi tindakan whistleblowing. Hasil penelitian Rahmadani dkk. (2018) memberikan hasil, yaitu intensitas moral memiliki pengaruh secara signifikan terhadap whistleblowing internal. Hasil penelitian Putra \& Hariyani (2018) memberikan hasil, yaitu personal cost memiliki pengaruh terhadap intensi untuk melakukan whistleblowing internal, sedangkan hasil penelitian Aliyah (2015), Lestari \& Yaya (2017), dan Prayogi \& Suprajitno (2020) memberikan hasil bahwa personal cost berpengaruh negatif dan signifikan terhadap minat melakukan whistleblowing. Kontribusi penelitian ini adalah perbedaan pada objek penelitian. Objek penelitian ini adalah OPD di Kabupaten Purbalingga.

Prosocial Organizational Behaviour Theory adalah teori ini menyatakan bahwa seseorang dalam suatu organisasi bertujuan untuk meningkatkan kesejahteraan semua anggota yang ada di dalam suatu organisasi tersebut. Oleh karena itu, seseorang yang berada dalam suatu organisasi mengungkapkan kecurangan yang dilakukan oleh anggota organisasi lain jika hal tersebut membahayakan kesejahteraan anggota organisasi lainnya (Brief \& Motowidlo, 1986). Perilaku prosocial suatu sikap atau perilaku yang bermanfaat positif bagi orang di lingkungan sekitar orang tersebut berinterakasi sosial ataupun bermanfaat positif bagi diri sendiri (Dozier \& Miceli, 1985).

Tindakan whistleblowing yang dilakukan oleh anggota organisasi bertujuan agar suatu organisasi terlindung dari perilaku yang tidak etis sehingga tujuan suatu organisasi dapat tercapai sesuai dengan aturan dan etika yang berlaku. Oleh karena itu, tindakan anggota organisasi harus dapat bermanfaat bagi organisasi itu sendiri, anggota organisasi, maupun whistleblower. Perilaku prososial adalah suatu sikap atau tindakan yang ditujukan untuk memberikan perlindungan atau pertolongan kepada orang lain dan tidak mengharapkan feedback dari apa yang telah dilakukan (Dozier \& Miceli, 1985).

Komitmen profesional adalah suatu keyakinan yang kuat dalam diri seseorang untuk bertindak dan berperilaku dalam menjalankan profesinya (Aranya dkk., 1981). Komitmen profesional mengharuskan seseorang untuk menjunjung tinggi nilai dan norma yang berlaku pada 
suatu organisasi atau profesi. Para anggota organisasi tersebut memiliki keyakinan dan usaha yang kuat untuk menjaga organisasi atau profesi yang ditekuni. Seseorang dengan tingkat profesionalisme yang tinggi akan melakukan tindakan pencegahan atas sikap yang tidak sejalan dengan nilai dan norma yang ada (Prayogi \& Suprajitno, 2020). Penelitian yang dilakukan oleh Joneta dkk. (2016), Pangesti \& Rahayu (2017), dan Prayogi \& Suprajitno (2020) menunjukkan bahwa komitmen profesional memiliki pengaruh positif terhadap whistleblowing. Hipotesis pertama penelitian ini adalah:

$\mathrm{H}_{1}$ : Komitmen profesional berpengaruh positif terhadap intensi untuk melakukan whistleblowing internal

Organisasi dengan lingkungan etika yang baik mendorong para anggota organisasi menjadi patuh dan taat pada nilai-nilai etis yang dapat mempengaruhi kualitas seseorang dalam bekerja serta mendorong untuk melakukan whistleblowing (Dalton \& Radtke, 2013). Penelitian yang dilakukan Hanif \& Odiatma (2017) dan Kristanti (2018) menunjukkan hasil bahwa lingkungan etika berpengaruh secara positif terhadap intensi whistleblowing. Hipotesis kedua penelitian ini adalah:

$\mathrm{H}_{2}$ : Lingkungan etika berpengaruh positif terhadap intensi untuk melakukan whistleblowing internal

Seseorang yang memiliki intensitas moral yang tinggi memiliki niat yang lebih besar untuk melakukan whistleblowing. Intensitas moral yang tinggi memunculkan rasa tanggungjawab (Husniati, 2017). Hasil penelitian yang dilakukan oleh Sari \& Ariyanto (2017) dan Amelia (2018) membuktikan bahwa intensitas moral berpengaruh positif terhadap whistleblowing. Hipotesis ketiga penelitian ini adalah:
$\mathrm{H}_{3}$ : Intensitas moral berpengaruh positif terhadap intensi untuk melakukan whistleblowing internal

Seseorang yang memiliki personal cost yang tinggi akan menunda bahkan tidak akan melakukan tindakan pelaporan pelanggaran (Busra dkk., 2019). Para anggota organisasi meyakini bahwa jika mereka melaporkan suatu tindakan menyimpang, maka pelaporan terhadap tindakan kecurangan tersebut akan diabaikan dan mereka tidak akan mendapatkan perlindungan dari manajer (Septiani, 2013). Hasil penelitian yang dilakukan oleh Lestari \& Yaya (2017) dan Oktavia (2018) membuktikan bahwa personal cost berpengaruh negatif terhadap whistleblowing. Hipotesis keempat penelitian ini adalah:

$\mathrm{H}_{4}$ : Personal cost berpengaruh negatif terhadap intensi untuk melakukan whistleblowing internal

Rangkaian hipotesis di atas membentuk suatu kerangka berpikir seperti pada Gambar 1.

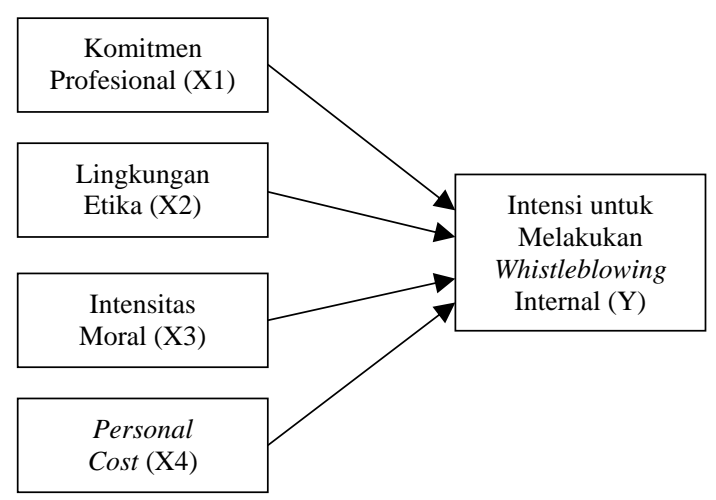

Gambar 1. Kerangka Berpikir

\section{METODE PENELITIAN}

Populasi yang digunakan penelitian ini adalah 27 Organisasi Perangkat Daerah (OPD) Kabupaten Purbalingga. Responden yang dipilih adalah aparatur pemerintah di OPD Kabupaten Purbalingga dengan kriteria kriteria, yaitu: (1) pegawai Eselon III dan Eselon IV, dan (2) masa kerja minimal 5 tahun di OPD yang sama. Teknik 
pengumpulan data dilakukan dengan menggunakan kuesioner dan kemudian kuesioner diberikan kepada responden sesuai dengan kriteria yang telah ditentukan. Variabel independen penelitian ini adalah Komitmen Profesional, Lingkungan Etika, Intensitas Moral, dan Personal Cost. Variabel dependen penelitian ini adalah Intensi untuk Melakukan Whistleblowingi Internal.

Indikator variabel komitmen profesional (X1) terdiri dari tingkat komitmen, rasa bangga dan persepsi seseorang terhadap organisasi atau profesinya. Indikator variabel lingkungan etika (X2) terdiri dari cara lingkungan tempat seseorang bekerja menjunjung tinggi nilai keadilan, kehormatan, dan kejujuran; adanya kode etik yang digunakan perusahaan sebagai alat kontrol perilaku karyawan; adanya kebijakan perusahaan untuk melindungi karyawan yang melaporkan masalah kecurangan atau pelanggaran; adanya pelatihan karyawan agar dapat berperilaku etis; adanya penghargaan sebagai sebuah motivasi bagi karyawan yang selalu berperilaku etis; adanya evaluasi kinerja disetiap akhir periode.

Indikator variabel intensitas moral (X3) terdiri dari anggota organisasi selalu mempertimbangkan moral adan etika yang berlaku saat menghadapi suatu masalah atau kasus dan dapat bertanggungjawab terhadap keputusan atau tindakan yang telah diperbuat. Indikator variabel personal cost (X4) terdiri dari keberanian seseorang untuk melaporkan jika diberikan skenario kasus penyalahgunaan asset, korupsi, dan fraud yang dinilai dengan menggunakan skala likert (1 sampai dengan 5). Indikator variabel dependen, yaitu intensi whistleblowing internal (Y) terdiri dari adanya niat dan keinginan untuk melakukan whistleblowing (Dalton \& Radtke, 2013).

Teknik analisis yang digunakan adalah analisis deskriptif untuk menghitung nilai minimum, maksimum, rata-rata, dan deviasi standar. Teknik analisis regresi linier berganda digunakan untuk menguji instrumen dan hipotesis penelitian. Uji instrumen terdiri dari uji validitas dan uji reliabilitas. Uji regresi linier berganda terdiri dari uji hipotesis dan uji asumsi klasik yang terdiri uji normalitas, uji heteroskedastisitas, uji autokorelasi, dan uji multikolinearitas.

\section{HASIL DAN PEMBAHASAN}

Penelitian dilaksanakan pada bulan April sampai bulan Juli 2020. Data kuesioner disebarkan kepada 97 responden dan sebanyak $60 \quad(81,1 \%)$ kuesioner dapat diolah. Karakteristik responden dibuat untuk memberi gambaran umum responden, seperti pada Tabel 1. Gender pada OPD Kabupaten Purbalingga didominasi oleh laki-laki yaitu sebesar $71,7 \%$. Tingkat pendidikan responden di OPD Kabupaten Purbalingga sebesar $56,67 \%$ adalah sarjana (S1). Sementara itu, $78,33 \%$ aparatur pemerintah di OPD Kabupaten Purbalingga menduduki jabatan sebagai staf dan sebesar $63,3 \%$ aparatur pemerintah di OPD Kabupaten Purbalingga menduduki jabatan struktural Eselon 3.

Tabel 1. Karakteristik Responden

\begin{tabular}{lrr}
\hline \multicolumn{1}{c}{ Karakteristik } & Kuantitas & Presentase \\
\hline Gender & & \\
$\quad$ Laki-laki & 43 & $71,70 \%$ \\
$\quad$ Perempuan & 17 & $28,30 \%$ \\
Pendidikan Terakhir & & \\
$\quad$ SMA/Sederajat & 7 & $11,66 \%$ \\
$\quad$ Diploma & 10 & $16,67 \%$ \\
$\quad$ Sarjana (S1) & 34 & $56,67 \%$ \\
$\quad$ Pascasarjana (S2) & 9 & $15,00 \%$ \\
Jabatan & & \\
$\quad$ Staf & 47 & $78,33 \%$ \\
$\quad$ Kasi & 8 & $13,33 \%$ \\
$\quad$ Kasubag & 5 & $8,34 \%$ \\
Eselon & & \\
$\quad$ Eselon 3 & 38 & $63,30 \%$ \\
Eselon 4 & 22 & $36,70 \%$ \\
\hline
\end{tabular}

Tabel 2 menunjukkan statistik deskriptif 60 responden penelitian. Statistik deskriptif menghitung nilai mininmum, maksimum, rata-rata, dan deviasi standar. Variabel komitmen profesional memiliki nilai minimum sebesar 17 , nilai maksimum sebesar 25, rata-rata sebesar 20,90, dan standar deviasi sebesar 2,275. Variabel 
lingkungan etika memiliki nilai minimum sebesar 19, nilai maksimum sebesar 35, rata-rata sebesar 27,63, dan standar deviasi sebesar 3,636. Variabel intensitas moral memiliki nilai minimum sebesar 16 , nilai maksimum sebesar 25, rata-rata sebesar 20,30, dan standar deviasi sebesar 2,586. Variabel personal cost memiliki nilai minimum sebesar 5, nilai maksimum sebesar 15, rata-rata sebesar 8,85, dan standar deviasi sebesar 2,146. Variabel intensi whistleblowing memiliki nilai minimum sebesar 28, nilai maksimum sebesar 40, rata-rata sebesar 32,43, dan standar deviasi sebesar 2,764.

Tabel 2. Statistik Deskriptif

\begin{tabular}{lcrrrr}
\hline & $\begin{array}{c}\text { Kuantitas } \\
\text { "N" }\end{array}$ & Min & Max & Mean & $\begin{array}{c}\text { Deviasi } \\
\text { Standar }\end{array}$ \\
\hline Komitmen Profesional (X1) & 60 & 17 & 25 & 20,90 & 2,275 \\
Lingkungan Etika (X2) & 60 & 19 & 35 & 27,63 & 3,636 \\
Intensitas Moral (X3) & 60 & 16 & 25 & 20,30 & 2,586 \\
Personal Cost (X4) & 60 & 5 & 15 & 8,85 & 2,146 \\
Intensi Whistleblowing (Y) & 60 & 28 & 40 & 32,43 & 2,764 \\
\hline Sumber: Data primer diolah (2020) & & & &
\end{tabular}

Tabel 3. Hasil Uji Validitas

\begin{tabular}{|c|c|c|c|}
\hline $\begin{array}{l}\text { Nomor } \\
\text { Item }\end{array}$ & Korelasi & P Value & Hasil \\
\hline $\mathrm{Y} 1$ & 0,575 & 0,000 & "Valid" \\
\hline Y2 & 0,592 & 0,000 & "Valid" \\
\hline Y3 & 0,599 & 0,000 & "Valid" \\
\hline Y4 & 0,572 & 0,000 & "Valid" \\
\hline Y5 & 0,602 & 0,000 & "Valid" \\
\hline Y6 & 0,662 & 0,000 & "Valid" \\
\hline Y7 & 0,384 & 0,002 & "Valid" \\
\hline Y8 & 0,585 & 0,000 & "Valid" \\
\hline X1.1 & 0,605 & 0,000 & "Valid" \\
\hline $\mathrm{X} 1.2$ & 0,687 & 0,000 & "Valid" \\
\hline $\mathrm{X} 1.3$ & 0,726 & 0,000 & "Valid" \\
\hline X1.4 & 0,685 & 0,000 & "Valid" \\
\hline $\mathrm{X} 1.5$ & 0,800 & 0,000 & "Valid" \\
\hline $\mathrm{X} 2.1$ & 0,881 & 0,000 & "Valid" \\
\hline $\mathrm{X} 2.2$ & 0,874 & 0,000 & "Valid" \\
\hline X 2.3 & 0,605 & 0,000 & "Valid" \\
\hline $\mathrm{X} 2.4$ & 0,770 & 0,000 & "Valid" \\
\hline X2.5 & 0,760 & 0,000 & "Valid" \\
\hline X2.6 & 0,623 & 0,000 & "Valid" \\
\hline $\mathrm{X} 2.7$ & 0,649 & 0,000 & "Valid" \\
\hline X3.1 & 0,502 & 0,000 & "Valid" \\
\hline X 3.2 & 0,637 & 0,000 & "Valid" \\
\hline X3.3 & 0,601 & 0,000 & "Valid" \\
\hline X3.4 & 0,878 & 0,000 & "Valid" \\
\hline X3.5 & 0,769 & 0,000 & "Valid" \\
\hline X4.1 & 0,811 & 0,000 & "Valid" \\
\hline $\mathrm{X} 4.2$ & 0,745 & 0,000 & "Valid" \\
\hline $\mathrm{X} 4.3$ & 0,849 & 0,000 & "Valid" \\
\hline
\end{tabular}

Pada penelitian yang sudah dilakukan, terdapat empat variabel independen dan satu variabel dependen. Hasil uji instrumen yang terdiri dari uji validitas dan uji reliabilitas yang dilakukan terhadap keseluruhan variabel tersebut dirangkum dalam Tabel 3.

Berdasarkan Tabel 3, seluruh pertanyaan untuk masing-masing variabel penelitian dinyatakan valid. Hal ini dibuktikan dengan nilai $\mathrm{P}$ value pada masing-masing item pertanyaan bernilai kurang dari 0,05.

Hasil uji reliabilitas pada Tabel 4 menunjukkan bahwa Cronbach alpha lebih dari 0,70. Hal ini menunjukkan bahwa semua semua responden cukup stabil dalam menjawab pertanyaan kuesioner dan kuesioner dinyatakan layak sebagai alat ukur.

Tabel 4. Hasil Uji Reliabilitas

\begin{tabular}{lcc}
\hline \multicolumn{1}{c}{ Variabel } & $\begin{array}{c}\text { Cronbach } \\
\text { Alpha }\end{array}$ & Hasil \\
\hline $\begin{array}{l}\text { Komitmen } \\
\text { Profesional (X1) }\end{array}$ & 0,707 & "Reliabel" \\
$\begin{array}{l}\text { Lingkungan } \\
\text { Etika (X2) }\end{array}$ & 0,859 & "Reliabel" \\
$\begin{array}{l}\text { Intensitas } \\
\text { Moral (X3) }\end{array}$ & 0,704 & "Reliabel" \\
$\begin{array}{l}\text { Personal } \\
\text { Cost (X4) }\end{array}$ & 0,722 & "Reliabel" \\
$\begin{array}{l}\text { Intensi } \\
\text { Whistleblowing (Y) }\end{array}$ & 0,703 & "Reliabel" \\
\hline Sumber: Data primer diolah (2020) &
\end{tabular}

Uji normalitas pada penelitian ini menggunakan metode Kolomogrov Smirnov. Nilai Kolmogorov Smirnov 
menunjukkan bahwa nilai signifikansi adalah 0,477 lebih besar daripada 0,05 sehingga data penelitian terdistribusi normal.

Tabel 5. Hasil Uji One-Sample Kolmogorov-Smirnov

\begin{tabular}{lc}
\hline Variabel & $\begin{array}{c}\text { Unstandardized } \\
\text { Residual }\end{array}$ \\
\hline $\mathrm{N}$ & 60 \\
Kolmogorov & \\
$\quad$ Smirnov Z & 0,842 \\
Asymp. & \\
Sig. (2-tailed) & 0,477 \\
\hline \multicolumn{2}{c}{ Sumber: Data primer diolah $(2020)$}
\end{tabular}

Uji heteroskedastisitas pada penelitian ini menggunakan uji Glejser. Hasil uji glejser semua variabel independen menunjukkan nilai lebih besar daripada 0,05 sehingga variabel komitmen profesional, lingkungan etika, intensitas moral, dan personal cost tidak terjadi masalah heterokedastisitas.

Tabel 6. Hasil Uji Glejser

\begin{tabular}{lc}
\hline \multicolumn{1}{c}{ Variabel } & Signifikansi \\
\hline Constant & 0,250 \\
Komitmen Profesional (X) & 0,674 \\
Lingkungan Etika (X2) & 0,775 \\
Intensitas Moral (X3) & 0,392 \\
Personal Cost (X4) & 0,389 \\
\hline
\end{tabular}

Sumber: Data primer diolah (2020)

Hasil uji autokorelasi menggunakan nilai Durbin-Watson (DW) yaitu sebesar 2,216. Jika nilai Durbin-Watson dibandingkan dengan nilai tabel signifikansi $5 \% \quad(0,05)$, jumlah sampel sebanyak 60 dan jumlah variabel independen sebanyak $4(K=4)$ atau sebesar 4,60, maka nilai dU dari tabel $\mathrm{r}$ adalah sebesar 1,727. Nilai Durbin-Watson lebih besar dari batas nilai dU dan kurang dari (4$\mathrm{dU})=4-1,727=2,273$ sehingga data penelitian ini dapat disimpulkan bahwa tidak terdapat autokorelasi.

Tabel 7. Hasil Uji Durbin-Watson

\begin{tabular}{lc}
\hline \multicolumn{1}{c}{ Variabel } & $\begin{array}{c}\text { Nilai } \\
\text { Durbin-Watson }\end{array}$ \\
\hline Durbin-Watson & 2,216 \\
\hline \multicolumn{2}{l}{ Sumber: Data primer diolah $(2020)$}
\end{tabular}

Hasil uji multikolinearitas menunjukkan bahwa nilai VIF variabel komitmen profesional adalah sebesar 1,116, nilai VIF variabel lingkungan etika adalah sebesar 1,141, nilai VIF intensitas moral adalah sebesar 1,030 , dan nilai VIF variabel personal cost adalah sebesar 1,014. Nilai VIF dari setiap variabel menunjukkan nilai yang lebih kecil dari 10. Oleh karena itu, seluruh variabel independen pada penelitian ini terbebas dari multikolinearitas.

Tabel 8. Hasil Uji Multikolinieritas

\begin{tabular}{lcc}
\hline Variabel & Tolerence & VIF \\
\hline $\begin{array}{l}\text { Komitmen } \\
\text { Profesional }\left(\mathrm{X}_{1}\right)\end{array}$ & 0,896 & 1,116 \\
Lingkungan & & \\
$\quad$ Etika (X2) & 0,876 & 1,141 \\
$\begin{array}{l}\text { Intensitas } \\
\quad \text { Moral (X3) }\end{array}$ & 0,971 & 1,030 \\
$\begin{array}{l}\text { Personal } \\
\quad \text { Cost (X4) }\end{array}$ & 0,986 & 1,014 \\
\hline \multicolumn{2}{l}{ Sumber: Data primer diolah (2020) } &
\end{tabular}

Hasil uji regresi linear berganda ditmapilkan dalam Tabel 9. Persamaan regresi linier berganda dapat dituliskan pada Persamaan (1).

$$
\begin{aligned}
\mathrm{Y}= & 7,129+0,403 \times \mathrm{X} 1+0,332 \times \mathrm{X} 2+ \\
& 0,235 \times \mathrm{X} 3+0,331 \times \mathrm{X} 4 \ldots \ldots \ldots \ldots(1)
\end{aligned}
$$

Nilai Adjusted $\mathrm{R}^{2}$ adalah 0,428. Hal ini menunjukkan bahwa semua variabel independen yang digunakan dalam penelitian ini dapat menjelaskan variabel dependen (whistleblowing internal) sebesar $42,8 \%$ dan sebesar $57,2 \%$ variabel dependen dalam penelitian ini dipengaruhi oleh variabel independen lain di luar penelitian ini.

Hasil pengujian hipotesis pertama $\left(\mathrm{H}_{1}\right)$ menunjukkan nilai signifikansi 0,002 < 0,05 , artinya komitmen profesional berpengaruh positif terhadap intensi untuk melakukan whistleblowing internal. Semakin tinggi komitmen profesional terhadap suatu organisasi, maka intensi seseorang untuk malakukan whistleblowing semakin besar. Para aparatur pemerintah yang ada di OPD Kabupaten Purbalingga memiliki niat yang sangat kuat untuk 
melaporkan segala kecurangan atau pelanggaran yang terjadi di lingkungan Pemerintahan Kabupaten Purbalingga. Penelitian ini sejalan dengan penelitian terdahulu bahwa komitmen profesional berpengaruh positif terhadap intensi untuk melakukan whistleblowing internal (Pangesti \& Rahayu, 2017).

Tabel 9. Hasil Uji Hipotesis Regresi Linier Berganda

\begin{tabular}{lcccc}
\hline \multicolumn{1}{c}{ Variabel } & B & t & P Value & Hasil Hipotesis \\
\hline (Constant) & 7,129 & 1,803 & 0,077 & \\
Komitmen Profesional (X1) & 0,403 & 3,188 & 0,002 & $\mathrm{H}_{1}$ Diterima \\
Lingkungan Etika (X2) & 0,332 & 4,156 & 0,000 & $\mathrm{H}_{2}$ Diterima \\
Intensitas Moral (X3) & 0,235 & 2,197 & 0,032 & $\mathrm{H}_{3}$ Diterima \\
Personal Cost (X4) & 0,331 & 2,593 & 0,012 & $\mathrm{H}_{4}$ Ditolak \\
\hline
\end{tabular}

F hitung $=12,029$

Sig.F $=0,000$

Adjusted $\mathrm{R}^{2}=0,428$

Sumber: Data primer diolah (2020)

Hasil pengujian hipotesis kedua $\left(\mathrm{H}_{2}\right)$ menunjukkan nilai signifikansi $0,000<$ 0,05 , artinya lingkungan etika berpengaruh positif terhadap intensi untuk melakukan whistleblowing. Semakin bagus lingkungan etika di sebuah organisasi, maka intensi seseorang untuk melakukan whistleblowing semakin besar. Para aparatur pemerintah yang ada OPD Kabupaten Purbalingga sangat menjunjung tinggi etika di dalam lingkungan kerja OPD Purbalingga. Oleh karena itu, para aparatur pemerintah yang ada di dalam organisasi ini memiliki rasa tanggungjawab untuk melakukan whistleblowing. Hasil penelitian mendukung penelitian (Kristanti, 2018) yang menyatakan lingkungan etika berpengaruh positif terhadap intensi untuk melakukan whistleblowing internal.

Hasil pengujian hipotesis ketiga $\left(\mathrm{H}_{3}\right)$ menunjukkan nilai signifikansi $0,032<$ 0,05 , artinya intensitas moral berpengaruh positif terhadap intensi untuk melakukan whistleblowing. Hal ini berarti semakin tinggi intensitas moral seseorang, maka intensi seseorang untuk melakukan whistleblowing pun ikut meningkat. Saat seseorang bertindak atau melakukan sesuatu, moral dijadikan suatu acuan atau dasar dalam bertindak. Seseorang yang sangat memegang teguh prinsip moral, maka tindakan yang dilakukan akan cenderung mengikuti moral yang berlaku. Hasil ini mendukung penelitian Sari \& Ariyanto (2017) yang menemukan 106 pengaruh positif intensitas moral terhadap whistleblowing internal.

Hasil pengujian hipotesis keempat $\left(\mathrm{H}_{4}\right)$ menunjukkan nilai signifikansi $0,012<0,05$, artinya bahwa personal cost berpengaruh positif terhadap intensi untuk melakukan whistleblowing. Hasil penelitian ini tidak mendukung hipotesis penelitian yang menyatakan bahwa personal cost berpengaruh negatif terhadap intensi melakukan whistleblowing. Semakin tinggi personal cost, maka intensi seseorang untuk melakukan whistleblowing juga meningkat. Para aparatur pemerintah yang bekerja di OPD Kabupaten Purbalingga memiliki keyakinan dan niat yang kuat sehingga tidak ada rasa takut terhadap ancaman yang ada jika melakukan pengungkapan tindakan kecurangan yang ada di lingkungan kerja OPD Kabupaten Purbalingga. Keyakainan para aparatur pemerintah OPD Kabupaten Purbalingga untuk melaporkan kecurangan yang terjadi dilindungi oleh landasan hukum yang ada, yaitu Peraturan Bupati nomor 30 tahun 2019 tentang pedoman penanganan pelaporan pengaduan dugaan tindak pidana korupsi di Kabupaten Purbalingga. Tujuan dikeluarkannya Peraturan Bupati tersebut adalah untuk melindungi para pelapor pelanggaran agar para pelapor tidak merasa takut untuk melaporkan kecurangan yang terjadi di Kabupaten Purbalingga. Hasil penelitian ini didukung oleh penelitian yang dilakukan oleh Kristanti (2018). 


\section{SIMPULAN DAN SARAN}

Penelitian ini bertujuan untuk meneliti determinan intensi untuk melakukan whistleblowing internal. Kesimpulan dari penelitian ini adalah komitmen profesional, lingkungan etika, intensitas moral, dan personal cost adalah determinan parsial yang memiliki arah positif terhadap intensi untuk melakukan whistleblowing internal di OPD Kabupaten Purbalingga.

Keterbatasan penelitian ini adalah variabel determinan intensi whistleblowing internal yang ada pada penelitian ini hanya berfokus pada komitmen profesional, lingkungan etika, intensitas moral, dan personal cost. Penelitian ini juga hanya dilakukan di OPD Kabupaten Purbalingga. Oleh karena itu, hasil penelitian ini tidak dapat digeneralisasi atau hasil penelitian ini tidak bisa digunakan digunakan oleh Pemerintah Daerah yang memiliki karakteristik berbeda dengan Pemerintah Daerah Kabupaten Purbalingga dan hasil penelitian ini tidak bisa digunakan untuk organisasi sektor swasta. Selain itu, pengumpulan data hanya dilakukan dnegan menggunakan kuesioner sehingga analisis yang dilakukan kurang mendalam karena keterbatasan data yang dimiliki oleh kuesioner.

Penelitian selanjutnya diharapkan dapat memilih lokasi penelitian selain pada sektor publik agar penelitian lebih bervariasi dan tidak terfokus hanya pada sektor publik saja. Selain itu, penelitian selanjutnya dapat dilakukan di OPD kabupaten atau kota lainnya yang ada di Indonesia. Penelitian selanjutnya juga dapat dilakukan dengan mengambil sampel di setiap Organisasi Pemerintah Provinsi atau Kabupaten di Indonesia agar hasil penelitian dapat lebih digeneralisasi atau digunakan oleh seluruh Pemerintah Provinsi atau Kabupaten yang ada di Indonesia.

Faktor-faktor yang r dapat
menimbulkan adanya intensi untuk
melakukan whistleblowing internal,
misalnya komitmen organisasi, sikap,
tingkat keseriusan kecurangan, sensitivitas

etis, locus of control, atau yang lainnya diharapkan bisa digunakan dalam penelitian selanjutnya. Penelitian selanjutnya juga diharapkan menggunakan metode lain selain metode kuesioner, seperti observasi untuk menambah dan memperbanyak data. Metode yang disarankan untuk penelitian selanjutnya selain observasi yaitu metode wawancara secara langsung sehingga jawaban responden lebih akurat.

Hasil penelitian ini diharapkan dapat meningkatkan niat dan kesadaran para aparatur pemerintah yang berada di OPD Kabupaten Purbalingga untuk terus dan tidak takut melaporkan jika ada kecurangan yang terjadi di lingkungan kerja OPD Kabupaten Purbalingga. Hal ini karena sudah ada landasan hukum yang melindungi para pelapor dari ancaman bahaya. Landasan hukum tersebut adalah Peraturan Bupati nomor 30 tahun 2019 tentang pedoman penanganan pelaporan pengaduan dugaan tindak pidana korupsi di Kabupaten Purbalingga. Selain itu, para aparatur pemerintah di Kabupaten Purbalingga dapat melakukan seleksi para calon pegawai dengan memperhatikan faktor-faktor yang mempengaruhi seseorang untuk melakukan intensi whistleblowing. Hal ini bertujuan agar kecurangan yang terjadi di lingkungan Pemerintahan Kabupaten Purbalingga dapat diminimalisasi sehingga para aparat pemerintah dapat mendukung tercapainya tujuan Pemerintah Kabupaten Purbalingga tanpa adanya kecurangan-kecurangan dalam bentuk apapun.

\section{REFERENSI}

Ahyaruddin, M., \& Asnawi, M. (2017). Pengaruh moral reasoning dan ethical environment terhadap kecenderungan untuk melakukan whistleblowing. Jurnal Akuntansi \& Ekonomika, 7(1), $1-20$.

Aliyah. (2015). Analisis faktor-faktor yang mempengaruhi minat pegawai dalam melakukan tindakan whistleblowing. Jurnal Dinamika Ekonomi \& Bisnis, 12(2). 173-189. 
Amelia, X. (2018). Pengaruh Intensitas Moral, Komitmen Profesional, Komitmen Organisasi, Dan Sensitivitas Etis Terhadap Whistleblowing (Studi Kasus Pada Perusahaan Unilever Di Kota Payakumbuh, Bukittinggi, dan Padang). JOM Fekon, 5.

Aranya, N., Pollock, J., \& Amernic, J. (1981). An examination of professional commitment in public accounting. Accounting, Organizations and Society, 6(4), 271-280.

Auzan, M. (2018). Evaluasi Implementasi Whistleblowing System pada PT Telekomunikasi Indonesia (Persero) Tbk. Skripsi. Universitas Brawijaya.

Brief, A. P., \& Motowidlo, S. J. (1986). Prosocial organizational behaviors. Academy of Management Review, 11(4), 710-725.

Busra, N. F., Ahyaruddin, M., \& Agustiawan, A. (2019). Pengaruh Tingkat Keseriusan Kecurangan, Personal Cost, dan Komitmen Organisasi Terhadap Kecenderungan Melakukan Whistleblowing. Muhammadiyah Riau Accounting and Business Journal, 1(1), 011-019.

Corruption Perceptions Index. (2019). Corruption Perceptions Index.

Dalton, D., \& Radtke, R. R. (2013). The joint effects of Machiavellianism and ethical environment on whistleblowing. Journal of business ethics, 117(1), 153-172.

Dozier, J. B., \& Miceli, M. P. (1985). Potential predictors of whistleblowing: A prosocial behavior perspective. Academy of Management Review, 10(4), 823-836.

Hanif, R. A., \& Odiatma, F. (2017). Pengaruh Lingukungan Etika Terhadap Niat Melakukan Whistleblowing dengan Locus of Control Sebagai Variabel Moderasi. Jurnal Akuntansi Keuangan dan Bisnis, 10(2), 61-69.

Husniati, S. (2017). Faktor-Faktor Yang Mempengaruhi Intensi Untuk
Melakukan Whistleblowing Internal (Studi Empiris Pada Satuan Kerja Perangkat Daerah Kabupaten Rokan Hulu). JOM Fekon, 4(1), 1223-1237. Janitra, W. A. (2017). Pengaruh Orientasi Etika, Komitmen Profesional, Komitmen Organisasi, Dan Sensitivitas Etis Terhadap Internal Whistleblowing. JOM Fekon, 4(1), 1208-1222.

Joneta, C., Anugerah, R., \& Susilatri, S. (2016). Pengaruh Komitmen Profesional Dan Pertimbangan Etis terhadap Intensi Melakukan Whistleblowing: Locus of Control sebagai Variabel Moderasi. JOM FEB, 3(1), 1960-1970.

Komite Nasional Kebijakan Governance. (2008). Pedoman Sistem Pelaporan Pelanggaran - SPP (Whistleblowing System-WBS).

Kreshastuti, D. K., \& Prastiwi, A. (2014). Analisis Faktor-faktor yang Mempengaruhi Intensi Auditor untuk Melakukan Tindakan Whistleblowing (Studi Empiris pada Kantor Akuntan Publik di Semarang). Diponegoro Journal Of Accounting, 3(2), 389403.

Kristanti. (2018). Analisis Pengaruh Personal Cost Dan Lingkungan Etika Terhadap Niat Melakukan Whistleblowing Dengan Locus Of Control Sebagai Variable Moderasi. Tesis. Universitas Islam Indonesia.

Lestari, R., \& Yaya, R. (2017). Whistleblowing dan faktor-faktor yang mempengaruhi niat melaksanakannya oleh aparatur sipil negara. Jurnal Akuntansi, 21(3), 336350 .

Oktavia, E. (2018). Pengaruh Personal Cost, Komitmen Organisasi, Sensitivitas Etis dan Machiavellian Terhadap Minat Melakukan Whistleblowing (Studi Empiris pada ASN di OPD Kota Pekanbaru). JOM FEB, 1(1), 1-15.

Pangesti, S. N., \& Rahayu, S. (2017). Pengaruh Komitmen Profesional Dan 
Sosialisasi Antisipatif Mahasiswa Akuntansi Terhadap Whistleblowing (studi Empiris Pada Mahasiswa Akuntansi Universitas Telkom Di Bandung Tahun Akademik 2015/2016). eProceedings of Management, 4(3), 2750-2761.

Prayogi, W. R., \& Suprajitno, D. (2020). Pengaruh Komitmen Profesional, Personal Cost, dan Moral Reasoning Terhadap Niat Seseorang untuk Melakukan Tindakan Whistleblowing. Jurnal Ilmiah Mahasiswa Manajemen, Bisnis dan Akuntansi (JIMMBA), 2(1), 10-16.

Putra, A. A., \& Hariyani, E. (2018). Pengaruh Komitmen Profesional, Lingkungan Etika, Intensitas Moral, Personal Cost Terhadap Intensi Untuk Melakukan Whistleblowing Internal (Studi Empiris Pada Opd Kabupaten Bengkalis). Jurnal Akuntansi Keuangan dan Bisnis, 11(2), 17-26.

Rahmadani, A., Hardi, H., \& Wiguna, M. (2018). Pengaruh Orientasi Etika Relativisme, Intensitas Moral, Komitmen Organisasi, Sifat Machiavellian dan Tingkat Keseriusan Kecurangan terhadap
Intensi untuk Melakukan Whistleblowing Internal (Studi Empiris pada OPD Kabupaten Rokan Hilir). JOM FEB, 1(1), 1-15.

Risalah, D. F. (2018, June 6). Bupati Purbalingga Resmi Tersangka. Republika, 8.

Sari, M. M. R., \& Ariyanto, D. (2017). Determinan Tindakan Whistleblowing. Jurnal Ekonomi dan Pariwisata, 12(1).

Schultz, J. J., Johnson, D. A., Morris, D., \& Dyrnes, S. (1993). An investigation of the reporting of questionable acts in an international setting. Journal of Accounting Research, 31, 75-103.

Suzila, S. (2018). Pengaruh sifat machiavellian dan lingkungan etika terhadap niat melakukan whistleblowing (Studi eksperimentasi pada SKPD di Lubuk Sikaping, Kabupaten Pasaman). Jurnal Akuntansi, 6(3), 1-11.

Zanaria, Y. (2016). Pengaruh Profesionalisme Audit, Intensitas Moral untuk Melakukan Tindakan Whistleblowing (Studi pada KAP di Indonesia). Akuisisi: Jurnal Akuntansi, 12(1). 
